\title{
Phospholipids of Haemophilus influenzae Rd during Exponential Growth and following the Development of Competence for Genetic Transformation
}

\author{
By SARAH L. SUTRINA AND J. J. SCOCCA \\ Department of Biochemical and Biophysical Sciences, \\ The Johns Hopkins University School of Hygiene and Public Health, \\ Baltimore, Maryland $2 \mathrm{I} 205$, U.S.A.
}

(Received I4 August 1975; revised 6 October 1975)

INTRODUCTION

In studies on the membrane constituents of Haemophilus influenzae Rd, we determined the phospholipid content of the organism and identified the phospholipids of $H$. influenzae as phosphatidyl ethanolamine $(85 \%)$ and phosphatidyl glycerol (15\%). Development of the ability to take up external transforming DNA (competence) did not affect this proportion.

\section{METHODS}

Cells were grown and made competent by the two-stage procedure of Herriott, Meyer \& Vogt (1970); the $\mathrm{P}_{\mathrm{i}}$ content of the stage I medium (heart infusion) was decreased to $0.4 \mu \mathrm{mol} / \mathrm{ml}$ as described by Scocca, Poland \& Zoon (1974), and the $\mathrm{P}_{\mathrm{i}}$ concentration of the stage II medium (M IV) was adjusted to this value. Sufficient ${ }^{32} \mathrm{P}_{\mathrm{i}}$ was added to give a specific activity of $5 \mathrm{Ci} / \mathrm{mol}$. Organisms grown and made competent in these media yielded I \% transformants to streptomycin resistance, indicating that nearly all the bacteria were capable of taking up DNA. Labelled cells were harvested by centrifuging and washed with $0.15 \mathrm{M}-\mathrm{NaCl}$; the phospholipids were extracted by a modification (Bertsch, Bonsen \& Kornberg, 1969) of the Bligh \& Dyer (1959) procedure, and concentrated by evaporation under $\mathrm{N}_{2}$.

Resolution of individual phospholipid classes was accomplished by thin-layer chromatography on silica gel plates (Chromagram polyvinyl alcohol binder, Eastman). Solvent A was chloroform-methanol-acetic acid $(65: 25: 8$, by vol.) and solvent B was chloroformmethanol-water $(65: 25: 4$, by vol.). Cardiolipin, phosphatidyl choline, phosphatidyl ethanolamine and phosphatidyl serine were purchased from Calbiochem and phosphatidyl glycerol and $\left.{ }^{32} \mathrm{P}\right]$ cardiolipin were prepared from Escherichia coli $\mathrm{B}$ by preparative thin-layer chromatography. Reagents were made to show up either by charring with $30 \%(\mathrm{v} / \mathrm{v})$ $\mathrm{H}_{2} \mathrm{SO}_{4}$, by exposure to $\mathrm{I}_{2}$ vapour, by Rhodamine $6 \mathrm{G}$ fluorescence, or with ninhydrin (for free amino groups). Labelled phospholipids were located by autoradiography, and quantified by counting the appropriate excised regions of the chromatograms. Mobilities on thin-layer plates were expressed relative to the mobility of cardiolipin, and designated $R_{\mathrm{Cl}}$. The relative mobilities of phosphatidyl ethanolamine and of cardiolipin under our conditions differed substantially from those reported elsewhere (e.g. Ames, I968), possibly because we used different thin-layer plates. All procedures used gave consistent results both with standard reagents and with phospholipid extracts from E. coli. 
Table I. Identification of phospholipids from exponential-phase H. influenzae by t.l.c.

Phospholipid
Cardiolipin
Phosphatidyl ethanolamine
Phosphatidyl glycerol
Phosphatidyl choline
Phosphatidyl serine
H. influenzae phospholipids
Major component
Minor component

\begin{tabular}{|c|c|}
\hline \multicolumn{2}{|c|}{$R_{\mathrm{C}}^{*}$} \\
\hline Solvent A & Solvent B \\
\hline 1.00 & $1 \cdot 00$ \\
\hline 0.73 & $1 \cdot 10$ \\
\hline 0.88 & 0.87 \\
\hline $0 \cdot 28$ & 0.65 \\
\hline 0.45 & 0.65 \\
\hline 0.73 & $\mathrm{I} \cdot 10$ \\
\hline 0.89 & 0.88 \\
\hline
\end{tabular}

$\begin{array}{cc}\begin{array}{c}\text { Ninhydrin } \\ \text { reaction }\end{array} & \begin{array}{c}\text { Rhodamine 6G } \\ \text { fluorescence }\end{array} \\ - & \text { Red } \\ + & \text { Yellow } \\ - & \text { Blue } \\ - & \text { Yellow } \\ + & \text { ND } \\ & \\ + & \text { Yellow } \\ - & \text { Blue }\end{array}$

* Mobility relative to cardiolipin. ND, not determined.

Table 2. Identification of the alkaline deacylation products from H. influenzae phospholipids

\begin{abstract}
Mobilities were determined using the solvent systems of Dawson (1960). Solvent I is phenol saturated with $\mathrm{H}_{2} \mathrm{O}$-acetic acid-ethanol (100:10:12, by vol.) Solvent 2 is methanol-formic acid $(88 \%, v / v)-\mathrm{H}_{2} \mathrm{O}(\mathrm{I} 60: 29: \mathrm{l})$. Standards were lccated by spraying with acid-molybdate; radioactive $H$. influenzae products were located by using a recording strip counter.
\end{abstract}

\section{Compound}

Glycerophosphorylglycerol Glycerophosphorylethanolamine

Glycerophosphorylserine

Glycerophosphorylcholine

Major $H$. influenzae product

Minor $H$. influenzae product

\begin{tabular}{|c|c|}
\hline \multicolumn{2}{|c|}{$R_{F}$} \\
\hline Solvent I & Solvent 2 \\
\hline 0.48 & $0.5 \mathrm{I}$ \\
\hline 0.62 & 0.38 \\
\hline 0.38 & - \\
\hline 0.92 & 0.60 \\
\hline 0.60 & 0.37 \\
\hline 0.46 & $0.5 \mathrm{I}$ \\
\hline
\end{tabular}

The identities of phospholipids were also established by comparison of deacylation products prepared by mild alkaline hydrolysis (Wells \& Dittmer, I966). The water-soluble products were identified by ascending chromatography on Whatman No. I paper (washed with $\mathrm{H}_{2} \mathrm{O}$ ), using two solvent systems (Dawson, 1960).

\title{
RESULTS AND DISCUSSION
}

The phospholipid fraction from both exponential-phase (density $10^{9}$ bacteria/ml) and competent $H$. influenzae accounted for 10 to $11 \%$ of the total dry weight of the cells, and was $0.16 \mathrm{mg} / \mathrm{mg}$ protein. The phospholipid content of cultures after development of competence increased $\mathrm{I} \cdot 5$-fold, thus paralleling the increase in protein in these cultures (Miller, 1970).

Chromatographic analyses of the phospholipids of exponential-phase $H$. influenzae revealed the presence of two components (Table 1): the major phospholipid was phosphatidyl ethanolamine, $85 \%$ of the total, and the minor component was phosphatidyl glycerol, $15 \%$. Substantial over-exposure of autoradiograms did not reveal additional components, indicating that no other phospholipid accounted for more than $0.1 \%$ of the total fraction.

The identification of the phospholipids was confirmed by comparison of the deacylated derivatives of the $H$. influenzae phospholipids with authentic standards. The results (Table 2), confirm the identification of the major component as phosphatidyl ethanolamine, and the lesser one as phosphatidyl glycerol. 
In view of our failure to observe cardiolipin in these extracts, and because of a report that H. influenzae possesses a powerful phospholipase D specific for cardiolipin (Ono \& White, 1970), we mixed $\left[{ }^{32} \mathrm{P}\right]$ cardiolipin with a non-radioactive pellet of $H$. influenzae and extracted the mixture. The added radioactivity was quantitatively recovered in the lipid fraction, and migrated as cardiolipin on t.l.c. The presence of cardiolipin in extracts of $H$. parainfluenzae was readily demonstrated. These findings, together with the absence of phosphatidic acid in extracts of $H$. influenzae, indicate that cardiolipin was stable in our extraction procedures and that it was absent from the membranes of $H$. influenzae.

The phospholipids synthesized during development of competence were identical to those made during exponential growth. Phosphatidyl ethanolamine accounted for $85.4 \pm \mathrm{I} \cdot 5 \%$ (mean \pm standard deviation for five determinations) of the total phospholipid labelled during growth, and $85.0 \pm \mathrm{I} \cdot 5 \%$ of the phospholipid labelled during development of competence in radioactive medium; the remaining fraction in both cases was phosphatidyl glycerol. Identical results were obtained when the organisms were labelled during growth and allowed to develop competence in non-radioactive medium.

Thanks are due to S. S. Krag and K. C. Zoon for their advice and to K. Moore for assistance in preparing the manuscript. This work was supported by the American Cancer Society (grant NP I2I). S. L.S. is a Worthington-Kunitz Fellow; J.J.S. has a Public Health Service Career Development Award from the National Institute of General Medical Sciences ( $\mathrm{K}_{4}-\mathrm{GM}$ 70663).

\section{REFERENCES}

AmEs, G. F. (1968). Lipids of Salmonella typhimurium and Escherichia coli: structure and metabolism. Journal of Bacteriology 95, 833-843.

Bertsch, L. L., Bonsen, P. P. M. \& Kornberg, A. ( 1969 ). Biochemical studies of bacterial sporulation and germination. XIV. Phospholipids of Bacillus megaterium. Journal of Bacteriology 98, 75-8I.

Bligh, E. G. \& Dyer, W. J. (I959). A rapid method of total lipid extraction and purification. Canadian Journal of Biochemistry and Physiology 37, 911-917.

Dawson, R. M. C. (1960). A hydrolytic procedure for the identification and estimation of individual phospholipids in biological samples. Biochemical Journal $\mathbf{7 4}, 45-53$.

Herriott, R. M., Meyer, E. M. \& Vogt, M. (1970). Defined non-growth media for stage 1 I development of competence in Haemophilus influenzae. Journal of Bacteriology ror, 5 I-524.

Miller, D. H. (1970). The involvement of inosine in the regulation of competence development in Haemophilus influenzae. Dissertation, The Johns Hopkins University, Baltimore.

Ono, Y., \& White D. C. (I970). Cardiolipin-specific phospholipase D activity in Haemophilus parainfluenzae. Journal of Bacteriology ro3, I I I-I I 5.

Scocca, J. J., Poland, R. L. \& Zoon, K. C. (1974). Specificity in deoxyribonucleic acid uptake by transformable Haemophilus influenzae. Journal of Bacteriology 118, 369-373.

Wells, M. A. \& Dittmer, J. C. (1966). A microanalytical technique for the quantitative determination of twenty-four classes of brain lipids. Biochemistry 5, 3405-34 I 8. 